\title{
Elevada frequência de Aeromonas spp. e genes de virulência em cultivos de tilápia-do-nilo (Oreochromis niloticus) em tanques-rede, na região semiárida de Pernambuco, Brasil
}

\author{
[High frequency of Aeromonas spp. and virulence genes in Nile Tilapia farms (Oreochromis niloticus) F.J.P. Kim1 \\ in semi-arid regions of Pernambuco, Brazil] $\quad$ https:///orcid.org/0000-0002-0002-474. \\ F.J.P. Kim ${ }^{1}$, A.E.M Silva ${ }^{2}$, R.V.S. Silva ${ }^{2}$, P.C.P. Kim ${ }^{2}$, A.C. Acosta $^{2}$, \\ S.M.B.C. Silva ${ }^{2}$, M.J. Sena ${ }^{2}$, R.A. Mota ${ }^{2}$ \\ https://orcid.org/0000-0001-8575-559X \\ https://orcid.o \\ https://orcid.org/0000-0003-0321-2685 \\ P.C.P. Kim2 \\ https://orcid.org/0000-0002-5180-045X \\ A.C. Acosta2 \\ https://orcid.org/0000-0002-8271-7923 \\ https://orcid.org/0000-0002-7571-3465 \\ ${ }^{1}$ Instituto Federal de Educação, Ciência e Tecnologia de Pernambuco - Barreiros, PE \\ ${ }^{2}$ Universidade Federal Rural de Pernambuco - Recife, PE

\section{RESUMO}

Objetivou-se avaliar a ocorrência de Aeromonas spp. em peixes e amostras de água na região semiárida de Pernambuco e avaliar a frequência de aerolissina (aerA), enterotoxina citotóxica (act), enterotoxina citotônica (alt) e serina protease ( $a h p$ ) nesses isolados. Foram analisados 70 peixes vivos e oito mortos com sinais clínicos de aeromoniose e 16 amostras de água. Aeromonas spp. foram identificadas por análises microbiológicas (provas bioquímicas) e molecular, usando-se primers específicos para a região 16S rRNA, e a distribuição dos quatro fatores de virulência (aerA, alt, act e ahp) foi investigada por ensaio de PCR. Cento e cinquenta e cinco $(84,7 \%)$ isolados foram confirmados como Aeromonas spp. na análise molecular. Os genes de virulência mais frequentes foram act $(53,55 \%)$ e aerA $(51,61 \%)$. De acordo com o tipo de amostra, observou-se maior frequência do gene aerA $(87,5 \% \mathrm{P}=0,0474)$ em isolados de peixes mortos e a menor frequência do gene act $(47,73 \% \mathrm{P}=0,0002)$ em peixes vivos. Este estudo demonstrou a presença de aeromoniose no cultivo de tilápias em tanques-rede, nos municípios de Jatobá e Petrolândia, na região semiárida de Pernambuco. A detecção de aerA, act e alt pode ser utilizada na tipagem de virulência de Aeromonas spp.

Palavra-chave: aeromoniose, fatores de virulência, Oreochromis niloticus, PCR

\begin{abstract}
The purpose of this study was to evaluate the occurrence of Aeromonas spp. from fishes and tilapia netcage farm water in semi-arid regions of Pernambuco and to evaluate the frequency of the aerolysin (aerA), cytotoxic enterotoxin (act), cytotonic enterotoxin (alt) and serine protease (ahp) genes in Aeromonas isolates. 70 live and eight dead fish with aeromoniosis clinical signs and 16 water samples were analyzed. Aeromonas spp. isolated were identified by microbiological (biochemical evidence) and molecular analysis using specific primers for 16SrRNA region, while the distribution of four virulence factors, including aerA, alt, act and ahp, was investigated by PCR assay. One hundred fifty-five (84.7\%) isolates were confirmed as Aeromonas spp. by molecular analysis. The most frequent virulence genes in isolates were act $(53.55 \%)$ and aerA (51,61\%). According to the kind of sample, the higher frequency of aerA gene $(87.5 \% P=0.0474)$ was observed in isolates from dead fish and the lowest frequency of act gene $(47.73 \% P=0.0002)$ from live fish. This study found the presence of aeromoniosis on tilapia farming in net-cages on Jatobá and Petrolândia counties in the semiarid Pernambuco region. The detection of aerA, act and alt can be used for virulence typing of Aeromonas spp. isolates.
\end{abstract}

Keywords: aeromoniosis, virulence factors, Oreochromis niloticus, $P C R$

Recebido em 17 de abril de 2018

Aceito em 25 de janeiro de 2019

E-mail: fernando_kim@barreiros.ifpe.edu.br 


\section{INTRODUÇÃO}

De acordo com os dados de produção pecuária fornecidos pelo Instituto Brasileiro de Geografia e Estatística em 2016, a tilápia foi a espécie mais produzida no Brasil, alcançando $47,1 \%$ de toda produção aquícola, atingindo 239,09 milhões de toneladas, com faturamento de 1,335 bilhão de reais (Produção..., 2016). Apesar dos dados animadores, os sistemas de piscicultura intensiva adotados no Brasil têm aumentado a incidência de doenças, principalmente de origem bacteriana, devido à maior densidade de estocagem, aos níveis elevados de matéria orgânica e à baixa qualidade do ambiente aquático, levando a altas taxas de mortalidade durante surtos (Sebastião et al., 2015). Kubitza (2013) estimou o impacto das enfermidades sobre o custo de produção da tilápia em tanques-rede, nas regiões Sudeste e Nordeste, e demonstrou perdas no Sudeste entre $\mathrm{R} \$ 0,49$ e $1,21 / \mathrm{kg}$ de peixe produzido vivo e, no Nordeste, entre R $\$ 0,54$ e $1,36 / \mathrm{kg}$ de peixe produzido vivo, dependendo da severidade e recorrência das enfermidades.

As bactérias de interesse para a piscicultura são consideradas oportunistas. Estão presentes na água e na microbiota dos peixes, podendo desencadear a doença em um hospedeiro debilitado por estresse provocado por alterações na qualidade da água, o que geralmente está associado à elevada densidade de peixe, entre outros fatores (Leira et al., 2016). Embora exista uma gama de agentes etiológicos com potencial patogênico para as tilápias-do-nilo, Aeromonas spp. e, em especial, Aeromonas hydrophila adquiriram maior importância pelas altas frequências observadas em vários estudos (Suhet et al., 2011; Sebastião et al., 2015).

Vários fatores de virulência foram descritos como importantes na participação da patogenia das infecções causadas por Aeromonas spp., sendo os mais estudados a aerolisina (AerA), a enterotoxina citotóxica (Act), a enterotoxina citotônica $(A l t)$ e a serina protease $(A h p)$. Estudos que avaliaram a presença dos genes codificantes desses fatores de virulência (aerA, act, alt, e $a h p$ ) observaram que genótipos positivos estavam mais frequentes em isolados obtidos de peixes doentes que de peixes sadios ou de amostras ambientais (Li et al., 2011; Hu et al., 2012). A disponibilidade do método analítico, como a $\mathrm{PCR}$, que permite avaliar o potencial patogênico das cepas de Aeromonas spp., pode aprimorar as estratégias de controle e prevenção de infecções por essas bactérias.

$\mathrm{Na}$ região semiárida do Nordeste, as cidades banhadas pelo rio São Francisco concentram uma ampla produção de tilápias cultivadas em tanques-rede, não existindo relatos sobre doenças que acometem os cultivos. O diagnóstico da aeromoniose muitas vezes é limitado, já que essa doença não possui sinais clínicos patognomônicos (Lemos et al., 2006). Os métodos microbiológicos convencionais de diagnóstico requerem tempo para serem realizados, contudo o uso de técnicas moleculares, como a reação em cadeia de polimerase (PCR), vem proporcionando maior rapidez e eficiência diagnóstica (González et al., 2004).

Objetivou-se neste estudo analisar a ocorrência de Aeromonas spp., por meio de técnicas microbiológica e molecular, em peixes e água dos estanques, e avaliar a frequência de genes que codificam fatores de virulência (aerA, act, alt $\mathrm{e}$ ahp) em isolados circulantes em tilapiculturas, na região semiárida do estado de Pernambuco.

\section{MATERIAL E MÉTODOS}

O estudo foi realizado no Laboratório de Doenças Infectocontagiosas dos Animais Domésticos da Universidade Federal Rural de Pernambuco, sob licença de número 117/2016, do Comitê de Ética e Uso Animal da Universidade Federal Rural de Pernambuco.

Foram visitadas duas tilapiculturas, nos municípios de Jatobá, e duas, em Petrolândia, totalizando quatro fazendas na região semiárida do estado de Pernambuco, abastecidas pelo rio São Francisco. As visitas foram realizadas nos meses de setembro e outubro de 2015. Todas as propriedades adotavam o cultivo intensivo em tanques-rede, com uso de ração comercial, e possuíam licenças ambientais expedidas pela Agência Estadual Pernambucana de Meio Ambiente. Para este estudo, as fazendas doaram 70 peixes vivos e oito peixes mortos, com pesos entre $300 \mathrm{~g}$ e $800 \mathrm{~g}$.

Durante a coleta, foi realizado exame clínico dos peixes vivos e anotados os sinais de alteração. 
Para a eutanásia, seguiu-se a metodologia descrita por Vidal et al. (2008), utilizando-se o anestésico eugenol, na concentração de $300 \mathrm{mg} / \mathrm{L}$, durante 10 minutos, em banho de imersão.

Para a coleta das amostras de água, assim como para as diluições seriadas para isolamento bacteriano, seguiu-se metodologia de Suhet et al. (2011). Foram coletadas 16 amostras de água (quatro amostras por fazendas), sendo duas do interior dos tanques-rede onde foram coletados os peixes e duas amostras no entorno dos tanques-rede. $\mathrm{O}$ transporte dos peixes e das amostras de água foi feito em caixas isotérmicas $\left(4-10^{\circ} \mathrm{C}\right)$ contendo gelo, imediatamente após as coletas.

Após a eutanásia dos peixes, foi realizada uma incisão na porção ventrolateral com o rebatimento dos tecidos anexos até a região das vísceras. Durante a necropsia, foram anotadas as lesões macroscópicas externas e internas. Para a coleta de amostras para o exame microbiológico, suabes estéreis foram friccionados na epiderme, nas brânquias, nos rins e nos intestinos. Os suabes foram mantidos em meio Brain Heart Infusion (BHI), a $4^{\circ} \mathrm{C}$, até o momento de seu processamento.

Para o isolamento e a caracterização bioquímica de Aeromonas spp., foi utilizada metodologia adaptada de Janda e Abbott (2010). As amostras foram semeadas em ágar MacConkey e incubadas por um período de $48 \mathrm{~h}$, a $28^{\circ} \mathrm{C}$, em estufa bacteriológica. As colônias sugestivas (com diâmetro entre 2 e $3 \mathrm{~mm}$, brilhantes, convexas (Janda e Abbott, 2010) e não fermentadoras de lactose (Matter et al., 2018)) foram submetidas às seguintes provas bioquímicas: catalase; hidrólise de esculina e ureia; produção de indol; produção de gás e ácido a partir da d-glicose e sacarose.

As colônias com características bioquímicas compatíveis com Aeromonas spp. foram ressuspendidas em $1,5 \mathrm{~mL}$ de caldo $\mathrm{BHI} \mathrm{e}$ incubadas a $28^{\circ} \mathrm{C}$, por $24 \mathrm{~h}$. $\mathrm{O}$ crescimento bacteriano foi acompanhado pela turbidez, na escala de Mc Farland, até atingir o número aproximado de $1,8 \times 10^{9}$ cél $/ \mathrm{mL}$. A extração de DNA genômico foi realizada por meio do uso do kit comercial "Qiagen DNA Easy Blood and Tissues" (Qiagen ${ }^{\circledR}$, Hilden, Germany), adotando-se protocolo descrito pelo fabricante.

Para confirmar os isolados obtidos na microbiologia como pertencentes ao gênero Aeromonas spp., foi utilizada a técnica de PCR convencional com base na análise de similaridade entre o DNA de Aeromonas spp., utilizando-se a ferramenta de pesquisa básica de alinhamento local (BLAST), disponível na base de dados GeneBank (https://blast.ncbi.nlm.nih.gov/Blast.cgi). Foi desenhado um par de primers específicos para o gênero Aeromonas, por meio do gene $16 \mathrm{~S}$ rRNA (Tab. 1). Outros genes codificantes para fatores de virulência também foram incluídos neste estudo, sendo os primers apresentados na Tab. 1.

Tabela 1. Primers utilizados na identificação de Aeromonas spp. e detecção genética de quatro fatores de virulência (aerA, act, alt e $a h p)$

\begin{tabular}{|c|c|c|c|c|}
\hline Gene & Sequência & Amplicon & $\mathrm{Ta}\left({ }^{\circ} \mathrm{C}\right)^{1}$ & Referência \\
\hline \multirow{2}{*}{$16 S-r R N A$} & F 5-TGACGTTACTCGCAGAGGA-3 & \multirow{2}{*}{$786 \mathrm{pb}$} & \multirow{2}{*}{$58,1^{\circ} \mathrm{C}$} & \multirow{2}{*}{ Estudo atual } \\
\hline & R 5-GCTTGCAGCCCTCTGTACG-3 & & & \\
\hline \multirow{2}{*}{ aerA } & F 5-GTACAACCTGGACCCTGACA-3 & \multirow{2}{*}{$550 \mathrm{pb}$} & \multirow{2}{*}{$59^{\circ} \mathrm{C}$} & \multirow{2}{*}{ Estudo atual } \\
\hline & R 5-CCCACTGGTAACGAATGCTG-3 & & & \\
\hline \multirow{2}{*}{$a c t$} & F 5-GAGAAGGTGACCACCAAGAACA-3 & \multirow{2}{*}{$232 \mathrm{pb}$} & \multirow{2}{*}{$58^{\circ} \mathrm{C}$} & \multirow{2}{*}{ (Hu et al., 2012) } \\
\hline & R 5-AACTGACATCGGCCTTGAACTC-3 & & & \\
\hline \multirow{2}{*}{ alt } & F 5-GGATGCCCTCAACACCATCA-3 & \multirow{2}{*}{$639 \mathrm{pb}$} & \multirow{2}{*}{$60^{\circ} \mathrm{C}$} & \multirow{2}{*}{ Estudo atual } \\
\hline & R 5-AACTCGTTGACGAAGCAGGT-3 & & & \\
\hline \multirow{2}{*}{ ahp } & F 5-ATTGGATCCCTGCCTA-3 & \multirow{2}{*}{$911 \mathrm{pb}$} & \multirow{2}{*}{$55^{\circ} \mathrm{C}$} & \multirow{2}{*}{ (Hu et al., 2012) } \\
\hline & R 5-GCTAAGCTTGCATCCG-3 & & & \\
\hline
\end{tabular}

${ }^{\mathrm{I}}$ Temperatura de anelamento. 
Como controle das reações, foram utilizadas cepas bacterianas de referência cedidas pela Fundação Oswaldo Cruz: Aeromonas hydrophila (ATCC 7966); Aeromonas sobria (ATCC 43979); Aeromonas media (ATCC 33907) e Aeromonas caviae (ATCC 15468), bem como dois isolados de campo de Aeromonas hydrophila, positivas para o gene aerA por PCR, provenientes do estudo de Oliveira et al. (2012).

Em todas as reações de PCR, foi utilizado o kit Promega ${ }^{\circledR}$ (PCR Master Mix) com volume final de $25 \mu \mathrm{L}$, sendo $12,5 \mu \mathrm{L}$ de GO Taq Green Master Mix; $1 \mu \mathrm{L}$ de cada primer nas concentrações de $10 \mathrm{pMol} / \mu \mathrm{L} ; 5 \mu \mathrm{L}$ de DNA e $5,5 \mu \mathrm{L}$ de água ultrapura tipo 1. Os perfis térmicos das reações de PCRs foram os seguintes: um ciclo inicial de $95^{\circ} \mathrm{C}$ por $10 \mathrm{~min}$; 30 ciclos de $95^{\circ} \mathrm{C}$ por um minuto, um minuto na temperatura de anelamento de cada par de primers (Tab. 1) e $72^{\circ} \mathrm{C}$ por um minuto; um ciclo de extensão final a $72^{\circ} \mathrm{C}$ por 10 minutos. A eletroforese foi realizada utilizando-se gel de agarose a $1,5 \%$; os produtos da PCR foram corados com BlueGreen (LGC®), visualizados em transiluminador e fotodocumentados sob luz UV. Para detecção de peso molecular específico para o fragmento amplificado pelos respectivos primers utilizados, usou-se um marcador de peso molecular de $100 \mathrm{pb}$ (Invitrogen) para comparações.

Na comparação de genes obtidos dos isolados de diferentes origens, foram aplicados os testes qui- quadrado e comparação múltipla de Duncan para comparação de diferenças estatísticas, utilizandose o pacote estatístico StatgraphicsCenturion XVI (versão 16.1.15, Statpoint Technologies Inc., Warrenton, Virginia); valores de $\mathrm{P} \leq 0,05$ foram considerados significativos.

\section{RESULTADOS}

Todos os peixes coletados neste estudo (78) apresentaram sinais clínicos de aeromoniose, com lesões de pele caracterizadas por áreas despigmentadas ou ulceradas, exoftalmia, ascite, petéquias viscerais, hepatomegalia, esplenomegalia, aumento de volume renal, rins friáveis e hemorragia na parede interna da cavidade abdominal. No exame microbiológico, todas as tilápias vivas e mortas apresentaram colônias compatíveis com Aeromonas spp. em um ou mais órgãos.

Os primers desenhados para a detecção de Aeromonas spp. (gene $16 S$ - rRNA) apresentaram resultados satisfatórios na amplificação da PCR, sendo confirmados $84,70 \%$ (155/183) isolados como pertencentes ao gênero Aeromonas (Tab. 2). Dos isolados confirmados como Aeromonas spp., 51,61\% (80/155) portavam o gene aerA. No caso do gene act, $53,55 \%$ (83/155) portavam esse gene, e $11,61 \%$ (18/155) foram positivos para o gene alt. Não foi observada a presença do gene ahp em nenhum dos isolados (Tab. 2).

Tabela 2. Identificação molecular dos isolados de Aeromonas spp. e detecção genética de quatro fatores de virulência nos isolados circulantes nos municípios de Jatobá e Petrolândia, PE

\begin{tabular}{|c|c|c|c|c|c|c|c|c|c|c|c|c|}
\hline \multirow{2}{*}{ Fazendas } & \multirow{2}{*}{$\begin{array}{l}\text { Tipos das } \\
\text { amostras }\end{array}$} & \multirow{2}{*}{$\begin{array}{l}\text { Colônias } \\
\text { presuntivas }\end{array}$} & \multicolumn{2}{|c|}{$16 S-r R N A$} & \multicolumn{2}{|c|}{ aerA } & \multicolumn{2}{|l|}{$a c t$} & \multicolumn{2}{|l|}{ alt } & \multicolumn{2}{|c|}{$a h p$} \\
\hline & & & $\mathrm{FA}^{1}$ & $\mathrm{FR}^{2}$ & FA & FR & FA & FR & FA & FR & FA & FR \\
\hline & P. Vivos ${ }^{4}$ & 43 & 36 & 83,72 & 13 & 36,11 & 1 & 2,78 & 4 & 11,11 & 0 & 0,00 \\
\hline \multirow[t]{3}{*}{$\mathrm{J} 1^{3}$} & P. Mortos & 2 & 2 & 100,00 & 2 & 100,00 & 2 & 100,00 & 0 & 0,00 & 0 & 0,00 \\
\hline & Água & 4 & 4 & 100,00 & 2 & 50,00 & 3 & 75,00 & 1 & 25,00 & 0 & 0,00 \\
\hline & P. Vivos & 63 & 53 & 84,13 & 32 & 60,38 & 38 & 71,70 & 4 & 7,55 & 0 & 0,00 \\
\hline \multirow[t]{3}{*}{$\mathrm{J} 2$} & P. Mortos & 2 & 2 & 100,00 & 1 & 50,00 & 2 & 100,00 & 0 & 0,00 & 0 & 0,00 \\
\hline & Água & 4 & 4 & 100,00 & 1 & 25,00 & 4 & 100,00 & 0 & 0,00 & 0 & 0,00 \\
\hline & P. Vivos & 35 & 29 & 82,86 & 17 & 58,62 & 10 & 34,48 & 5 & 17,24 & 0 & 0,00 \\
\hline \multirow[t]{3}{*}{ P1 } & P. Mortos & 2 & 2 & 100,00 & 2 & 100,00 & 2 & 100,00 & 0 & 0,00 & 0 & 0,00 \\
\hline & Água & 4 & 3 & 75,00 & 1 & 33,33 & 3 & 100,00 & 0 & 0,00 & 0 & 0,00 \\
\hline & P. Vivos & 18 & 14 & 77,78 & 6 & 42,86 & 14 & 100,00 & 4 & 28,57 & 0 & 0,00 \\
\hline \multirow[t]{2}{*}{$\mathrm{P} 2$} & P. Mortos & 2 & 2 & 100,00 & 2 & 100,00 & 2 & 100,00 & 0 & 0,00 & 0 & 0,00 \\
\hline & Água & 4 & 4 & 100,00 & 1 & 25,00 & 2 & 50,00 & 0 & 0,00 & 0 & 0,00 \\
\hline Total & & 183 & 155 & 84,70 & 80 & 51,61 & 83 & 53,55 & 18 & 11,61 & 0 & 0,00 \\
\hline
\end{tabular}

${ }^{1}$ Frequência absoluta (FA); ${ }^{2}$ frequência relativa (FR); ${ }^{3}$ fazendas dos municípios de Jatobá (J1 e J2) e Petrolândia (P1 e $\mathrm{P} 2) ;{ }^{4}$ peixes vivos (P. vivos) e peixes mortos (P. Mortos).

Nas quatro fazendas estudadas, a distribuição dos genes para os fatores de aerA e alt foi similar nos isolados $\quad(\mathrm{P}=0,2627 \quad$ e $\quad \mathrm{P}=0,2875$, respectivamente) (Tab. 3) e observou-se diferença significativa $(\mathrm{P}=0,0000)$ na frequência do gene act nos isolados circulantes. A menor 
frequência observada foi para os isolados da fazenda J1 (Jatobá 1; 14,29\%), seguida pela frequência da fazenda P1 (Petrolândia 1; $44,12 \%$ ) e finalmente pelas frequências de $\mathrm{J} 2$ e
P2, com 78,58\% e 90\%, respectivamente (Tab. 3). Esses resultados sugerem que isolados circulantes nas fazendas J2 e P2 são potencialmente mais virulentos.

Tabela 3. Frequência de genes fatores de virulência em isolados de Aeromonas spp. circulantes nos municípios de Jatobá e Petrolândia, PE

\begin{tabular}{llllllll}
\hline \multirow{2}{*}{ Fazendas } & $16 S-r R N A$ & aerA & & act & \multicolumn{3}{c}{ alt } \\
\cline { 2 - 7 } & FA & FA $^{1}$ & FR $^{2}$ & FA & FR & FA & FR \\
\hline $\mathrm{J}^{3}$ & 42 & 17 & 40,48 & 6 & $14,29^{\mathrm{a} 4}$ & 5 & 11,90 \\
$\mathrm{~J} 2$ & 59 & 34 & 57,63 & 44 & $74,58^{\mathrm{b}}$ & 4 & 6,78 \\
$\mathrm{P} 1$ & 34 & 20 & 58,82 & 15 & $44,12^{\mathrm{c}}$ & 5 & 14,71 \\
$\mathrm{P} 2$ & 20 & 9 & 45,00 & 18 & $90,00^{\mathrm{b}}$ & 4 & 20,00 \\
p-valor & & 0,2627 & & 0,0000 & & 0,2875 & \\
\hline
\end{tabular}

${ }^{\mathrm{P}}$ Frequência absoluta (FA); ${ }^{2}$ frequência relativa (FR); ${ }^{3}$ fazendas dos municípios de Jatobá (J1 e J2) e Petrolândia (P1 e P2). ${ }^{4}$ Letras diferentes representam diferenças estatísticas significativas $\alpha=0,05$.

As frequências dos genes para os fatores de virulência pelo tipo de amostra de origem não mostraram diferenças significativas para o gene alt $(\mathrm{P}=0,3055)$ (Tab. 4). No caso do gene aerA, a maior frequência foi observada em isolados obtidos de peixes mortos $(87,50 \%)$. Para o gene $a c t$, as maiores frequências foram observadas em isolados obtidos de peixes mortos $(100 \%)$ e água coletada nos tanques (80\%) (Tab. 4).

Tabela 4. Frequência de genes fatores de virulência em isolados de Aeromonas spp. nos diferentes tipos de amostras

\begin{tabular}{llllllll}
\hline Tipos das & $16 S-r R N A$ & AerA & & act & alt & \\
amostras & FA & $\mathrm{FA}^{1}$ & $\mathrm{FR}^{2}$ & FA & FR & FA & FR \\
\hline P. Vivos & 132 & 68 & $51,52^{\mathrm{a}^{4}}$ & 63 & $47,73^{\mathrm{a}}$ & 17 & 12,88 \\
P. Mortos & 8 & 7 & $87,50^{\mathrm{b}}$ & 8 & $100,00^{\mathrm{b}}$ & 0 & 0,00 \\
Água $_{\text {p-valor }}^{15}$ & 5 & $33,33^{\mathrm{a}}$ & 12 & $80,00^{\mathrm{b}}$ & 1 & 6,67 \\
\hline
\end{tabular}

${ }^{1}$ Frequência absoluta (FA); ${ }^{2}$ frequência relativa (FR); ${ }^{3}$ peixes vivos (P. Vivos) e peixes mortos (P. Mortos). ${ }^{4}$ Letras diferentes representam diferenças estatísticas significativas $\alpha=0,05$.

\section{DISCUSSÃO}

Dong et al. (2015) afirmaram que as condições de cultivo e estresse podem levar ao aumento no número de casos de doenças causadas por bactérias residentes nos peixes ou na água, sendo frequentemente observadas infecções múltiplas por bactérias nas quais Aeromonas spp. têm um importante papel. Todos os peixes coletados apresentaram quadro clínico compatível com aeromoniose de acordo com a descrição feita por Figueiredo e Leal (2008). A presença dessa bactéria associada às lesões foi confirmada por PCR para a maioria dos isolados de Aeromonas spp. obtidos dos cultivos da epiderme, das brânquias, do rim e do intestino dos peixes vivos e mortos.

A aerolisina (aerA) é o membro modelo de uma superfamília de toxinas $\beta$-porinas cuja estrutura conduz à inserção de um cilindro transmembranar nas células do hospedeiro (Degiacomi et al., 2013). A enterotoxina citotóxica (act), assim como a aerolisina, também é uma porina e pode provocar a degeneração das criptas e vilosidades do intestino delgado, desempenhando um importante papel em infecções por Aeromonas por induzir o início da sinalização do processo de apoptose em células eucarióticas (Tomás, 2012; Grim et al., 2013; Rasmussen-Ivey et al., 2016). No presente estudo, foram encontradas altas frequências genes aerA e act. Hu et al. (2012) e Ye et al. (2013) estudaram diversos genes para fatores de virulência em isolados de Aeromonas hydrophila obtidos de peixes doentes e relataram altas frequências desses genes. Resultados similares foram obtidos por Oliveira et al. (2012), que estudaram isolados de Aeromonas hydrophila provenientes de peixes clinicamente 
sadios. Ainda, neste estudo, altas frequências dos genes aerA $(87,5 \%)$ e act $(100 \%)$ foram detectadas em peixes mortos, sendo esse resultado já esperado, uma vez que a doença pode ter sido a causa do óbito desses peixes, o qual está geralmente associado a cepas mais virulentas. Também foi observada uma alta frequência do gene act nos isolados de amostras de águas dos estanques (80\%), sendo um aspecto preocupante, pois demonstra o elevado potencial patogênico de Aeromonas spp. e sugere elevada capacidade de causar aeromoniose nas tilápias dessa região.

A enterotoxinacitotônica (alt) tem mecanismos de ação semelhante à toxina colérica, aumentando os níveis de AMPc e prostaglandinas nas células epiteliais intestinais (Tomás, 2012). Estudos anteriores mostraram que a patogenicidade de Aeromonas spp. é complexa e multifatorial, podendo envolver a atividade de diferentes genes com atuação isolada ou combinada com outros genes (Galindo et al., 2006; Sha et al., 2009). Os resultados de Li et al. (2011) sugerem que o gene alt atua como coadjuvante para outros fatores de virulência na infecção por Aeromonas spp., não sendo um fator de virulência indispensável no mecanismo da infecção, o que poderia explicar as baixas frequências encontradas em estudo efetuado por Ye et al. (2013) e no presente trabalho.

A serina protease $(a h p)$ tem sido associada à ativação da aerolisina e outras enzimas com atividade proteolítica extracelular, aumentando, assim, a virulência do gênero Aeromonas (Li et al., 2011). Entretanto, o gene $a h p$ não é considerado essencial para a virulência dessa bactéria (Rasmussen-Ivey et al., 2016) e, neste sentido, são compreensíveis os resultados obtidos neste estudo, em que não foram observados isolados portadores desse gene. Os resultados obtidos por Li et al. (2011) demonstraram que os incrementos na presença dos genes para os fatores de virulência estão associados ao incremento de produtos extracelulares de atividade proteolítica, hemolítica e citotóxica. $\mathrm{O}$ estudo de genes que codificam os fatores de virulência permite avaliar o potencial de virulência das cepas circulantes, sendo a PCR a metodologia mais simples se comparada com metodologias que avaliam a expressão e a atividade das toxinas alvos de estudo. Os resultados obtidos nas fazendas $\mathrm{J} 2$ e $\mathrm{P} 2 \mathrm{em}$ relação ao gene act sinalizam que os isolados circulantes seriam potencialmente mais virulentos, o que constitui um alerta para o reforço das medidas de manejo.

Ismail et al. (2016) estudaram a associação entre a qualidade da água e as bactérias encontradas em cultivos de tilápia nilótica (Oreochromis niloticus) e vermelha (Oreochromis mossambicus) e relataram que a presença de bactérias patogênicas isoladas está associada principalmente à temperatura e à concentração de amônia na água.

As tilapiculturas visitadas neste estudo não utilizavam a imunoprofilaxia como método de prevenção dessa bacteriose, restringindo-se apenas ao uso de medidas de manejo, como a diminuição da taxa de estocagem em cada tanque-rede; o acompanhamento diário da mortalidade de cada tanque, com retirada dos peixes mortos e doentes quatro vezes por dia; o isolamento em local adequado dos insumos utilizados; a aquisição de alevinos sadios e sem sinais clínicos de aeromoniose. Por se tratar de bactérias ubíquas do ambiente aquático, a facilidade da disseminação de Aeromonas spp. pode ser agravada pelas mudanças na qualidade da água associadas à virulência dos isolados. Estudos sistemáticos sobre a distribuição de genes que codificam para fatores de virulência permitem avaliar o potencial de virulência das cepas circulantes em determinada fazenda ou região, contribuindo, assim, com os programas de controle dessa doença.

\section{CONCLUSÃO}

Este estudo foi o primeiro a demonstrar alta frequência de aeromoniose nos cultivos de tilápia em tanques-rede, na região semiárida de Pernambuco. Foi constatado considerável potencial de virulência das cepas de Aeromonas spp. isoladas da água dos tanques-rede e dos peixes, o que sugere a necessidade de inclusão de novas estratégias de controle e profilaxia da aeromoniose que visem ao cultivo sustentável na presença dessas bactérias. 


\section{AGRADECIMENTOS}

À Facepe, pela concessão das bolsas PIBIC (BIC-1862-5.05/15 e BIC-1891-5.05/15); ao professor Mateus Matiuzzi Costa, da Universidade Federal do Vale do São Francisco (Univasf), e à Fundação Oswaldo Cruz, pelas cepas bacterianas de referência cedidas.

\section{REFERÊNCIAS}

DEGIACOMI, M.T.; IACOVACHE, I.; PERNOT, L. et al. Molecular assembly of the aerolysin pore reveals a swirling membrane-insertion mechanism. Nat. Chem Biol., v.9, p.623-629, 2013.

DONG, H.T.; NGUYEN, V.V.; LE, H.D. et al. Naturally concurrent infections of bacterial and viral pathogens in disease outbreaks in cultured Nile tilapia (Oreochromis niloticus) farms. Aquaculture, v.448, p.427-435, 2015.

FIGUEIREDO, H.C.P.; LEAL, C.A.G. Tecnologias aplicadas em sanidade de peixes. Rev. Bras. Zootec., v.37, p.8-14, 2008.

GALINDO, C.L.; SHA, J.; FADL, A.A. et al. Host immune responses to Aeromonas virulence factors. Curr. Immunol. Rev., v.2, p.13-26, 2006.

GONZÁLEZ, S.F.; KRUG, M.J.; NIELSEN, M.E. et al. Simultaneous detection of marine fish pathogens by using multiplex PCR and a DNA microarray. $J$. Clin. Microbiol., v.42, p.1414-1419, 2004.

GRIM, C.J.; KOZLOVA, E.V.; SHA, J. et al. Characterization of Aeromonas hydrophila wound pathotypes by comparative genomic and functional analyses of virulence genes. Mbio, v.4, p.e00064-13, 2013.

HU, M.; WANG, N.; PAN, Z. et al. Identity and virulence properties of Aeromonas isolates from diseased fish, healthy controls and water environment in China. Lett. Appl. Microbiol., v.55, p.224-233, 2012.

ISMAIL, N.I.A.; AMAL, M.N.A.; SHOHAIMI, S. et al. Associations of water quality and bacteria presence in cage cultured red hybrid tilapia, Oreochromis niloticus $\times$ O. mossambicus. Aquacul. Rep., v.4, p.57$65,2016$.

JANDA, J.M.; ABBOTT, S.L. The genus Aeromonas: taxonomy, pathogenicity, and infection. Clin. Microbiol. Rev., v.23, p.35-73, 2010.

KUBITZA, F. Nutrição e saúde no cultivo de Tilápias. Panorama Aquicul., v.23, p.14-23, 2013.
LEIRA, M.H.; ASSIS LAGO, A.; BOTELHO, H.A. et $a l$. Principais infecções bacterianas na criação de peixes de água doce do Brasil-uma revisão. Rev. Ciênc. Vet. Saúde Pública, v.3, p.44-59, 2016.

LEMOS, J.B.; RODRIGUES, M.E.B.; LOPES, J.P. Diagnóstico de ectoparasitas e bactérias em tilápias (Oreochromis niloticus) cultivadas na região de Paulo Afonso, Bahia. Rev. Bras. Engen. Pesca, v.1, p.75-90, 2006.

LI, J.; NI, X.; LIU, Y. et al. Detection of three virulence genes alt, ahp and aerA in Aeromonas hydrophila and their relationship with actual virulence to zebrafish. J. Appl Microbiol., v.110, p.823-830, 2011.

MATTER, A.F.; EL ASELY, A.M.; SHAHEEN, A.A. et al. Phenotypic and molecular characterization of bacterial pathogens isolated from diseased freshwater fishes. Int. J. Fish. Aquatic Stud., v.6, p.34-41, 2018.

OLIVEIRA， S.T.; VENERONI-GOUVEIA， G.; COSTA, M.M. Molecular characterization of virulence factors in Aeromonas hydrophila obtained from fish. Pesqui. Vet. Bras., v.32, p.701-706, 2012.

PRODUÇÃO da pecuária municipal. Rio de Janeiro: IBGE, 2016. v.44, 53p.

RASMUSSEN-IVEY, C.R.; FIGUERAS, M.J.; MCGAREY, D. et al. Virulence factors of Aeromonas hydrophila: in the wake of reclassification. Front. Microbiol., v.7, p.1-10, 2016.

SEBASTIÃO, F.A.; FURLAN, L.R.; HASHIMOTO, D.T. et al. Identification of bacterial fish pathogens in Brazil by direct colony PCR and 16S rRNA gene sequencing. Adv. Microbiol., v.5, p.409-424, 2015.

SHA, J.; EROVA, T.E.; ALYEA, R.A. et al. Surfaceexpressed enolase contributes to the pathogenesis of clinical isolate SSU of Aeromonas hydrophila. J. Bacteriol., v.191, p.3095-3107, 2009.

SUHET, M.; SCHOCKEN-ITURRINO, R.; AMARAL, L. Atividade hemolítica e resistência a antimicrobianos por Aeromonas spp. isoladas de criação intensiva de tilápias do nilo (Oreochromis niloticus). Ars Vet., v.27, p.36-44, 2011.

TOMÁS, J. The main Aeromonas pathogenic factors. ISRN Microbiol., v.2012, p.1-22, 2012.

VIDAL, L.V.O.; ALBINATI, R.C.B.; ALBINATI, A.C.L. et al. Eugenol como anestésico para a tilápiado-nilo. Pesqui. Agropecu. Bras., v.43, p.1069-1074, 2008.

YE, Y.; FAN, T.; LI, H. et al. Characterization of Aeromonas hydrophila from hemorrhagic diseased freshwater fishes in Anhui Province, China. Int. Food Res. J., v. 20, n. 3, p. 1449-1452, 2013. 